\title{
Robert Eichler*
}

\section{The periodic table - an experimenter's guide to transactinide chemistry}

\author{
https://doi.org/10.1515/ract-2018-3080 \\ Received November 14, 2018; accepted February 18, 2019; published \\ online March 16, 2019
}

\begin{abstract}
The fundamental principles of the periodic table guide the research and development of the challenging experiments with transactinide elements. This guidance is elucidated together with experimental results from gas phase chemical studies of the transactinide elements with the atomic numbers 104-108 and 112-114. Some deduced chemical properties of these superheavy elements are presented here in conjunction with trends established by the periodic table. Finally, prospects are presented for further chemical investigations of transactinides based on trends in the periodic table.
\end{abstract}

Keywords: Periodic table, trends, transactinides, gas phase, predictions.

\section{Introduction}

The periodic table is the most fundamental ordering scheme of the 118 chemical elements currently known. Elements with comparable chemical properties were the initial reason already in 1869 for Mendeleev [1, 2] to shape the periodic table similar to the one we know today. At this time, nothing was known about atomic structure and particularly about electrons governing the chemical properties of the elements. However, also the development of our knowledge about atomic and electronic structure did not change the scope and principal arrangements in the periodic table, exhibiting the fundamentality of Mendeleev's discovery, who had at hand only 66 elements.

Figure 1 shows today's periodic table as approved by the International Union of Pure and Applied Chemistry (IUPAC). The elements featuring the very edges of the periodic table have particularly exciting properties:

- $\mathrm{H}$ and He placed on the upper edge, being the most abundant atomic matter in our universe, are special elements regarding physical and chemical properties. Hydrogen occurs in compounds either as $\mathrm{H}^{+}$,

*Corresponding author: Robert Eichler, Laboratory of Radiochemistry, Paul Scherrer Institute, Forschungsstrasse 111, 5232 Villigen PSI, Switzerland, E-mail: robert.eichler@psi.ch typical for alkali metals, or as $\mathrm{H}^{-}$, similar to halogens. It becomes metallic at high pressures [3]. Helium has the most enhanced chemical inertness amongst all elements with the highest first ionization potential and lowest polarizability leading to an extremely low boiling point of $-268.9^{\circ} \mathrm{C}$, close to absolute zero. Furthermore, it shows a rare state of superfluidity as a liquid below $\sim-271^{\circ} \mathrm{C}$.

- The group of alkali metals exhibited at the left-hand edge of the periodic table represents the most reactive metals with increasing reactivity along the group. The heavier members even ignite at room temperature in contact with air.

- $\quad$ On the right-hand edge of the periodic table the group of noble gases reveals unprecedented atomic stabilities and thus exceptional chemical inertness, fading along the group, though.

- The lower edge of the periodic table is home of the heaviest elements, known as transactinide elements (TA) or superheavy elements (SHE). The TA series includes elements from various groups of the periodic table (see Figure 1).

This work intends to introduce some of the challenges to experimentally address chemical properties of these elements. These efforts are guided by principles of the periodicity. Therefore, some experimentally derived chemical properties will be presented in comparison to expectations from chemical trends established in the corresponding groups of the periodic table.

\section{Trends in the periodic table}

The concept of groups in the periodic table means not only that elements with similar chemical properties belong to one group (column) but also that there are trends established for these properties evolving along the groups. Typical properties for which such trends have been established within the groups containing transactinide elements are listed in Figure 2: e.g. for transition metals of groups 4-8 the trend of increasing stability of the compounds with highest oxidation states is observed. Vice versa the stability of the lower oxidation states decrease. The volatility of the compounds with the highest oxidation 

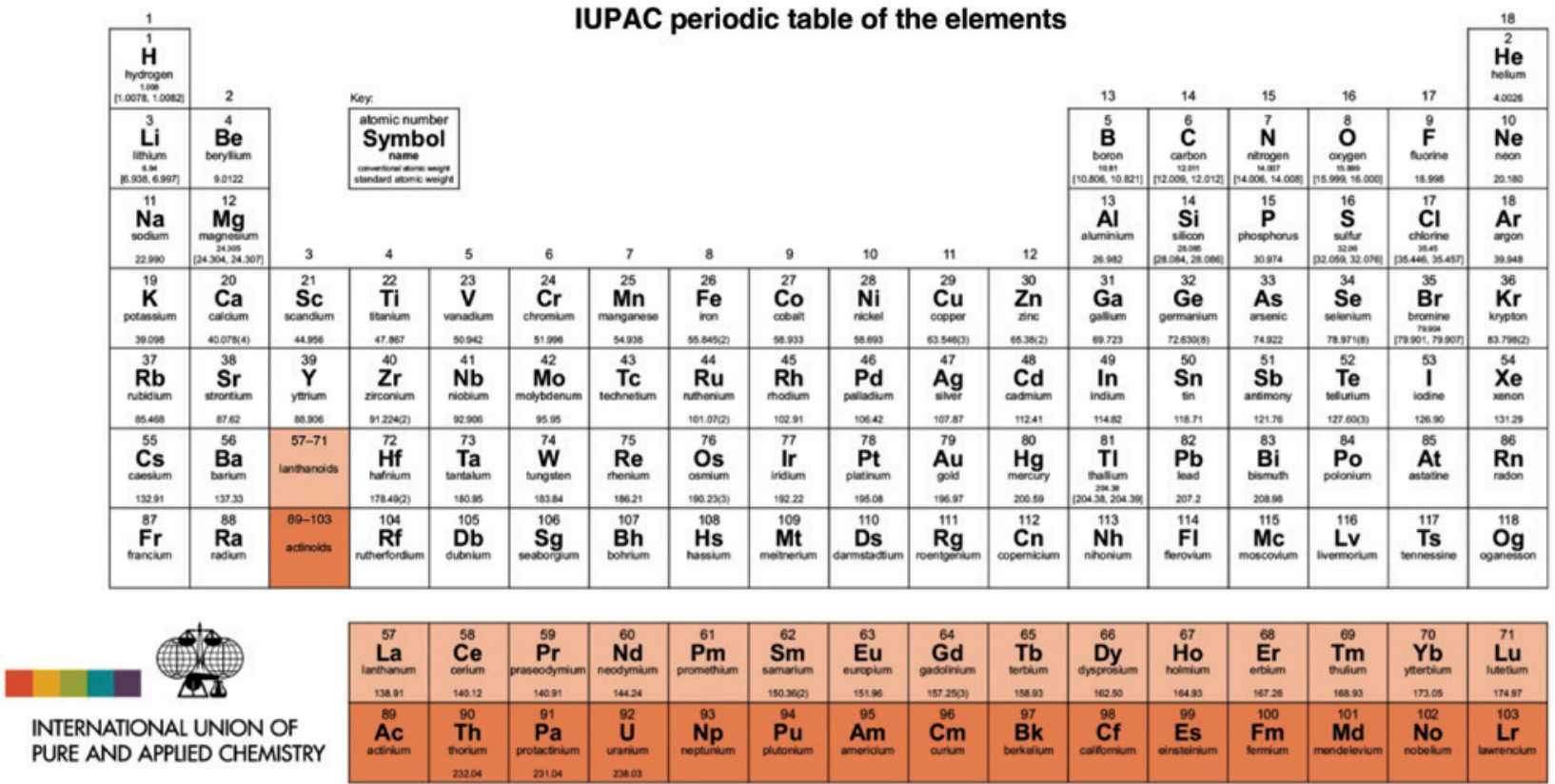

Figure 1: The IUPAC periodic table of the elements [https://iupac.org/what-we-do/periodic-table-of-elements/].

Atomic number

Atomic radius

Number of protons in Radius of the outer the atomic nucleus, valence electron of the i.e. its positive charge, Z atom

rA lonic radius

Radius of the outer electron of an ion, $\mathrm{ri}$
Ionization potential

Energy required to

from the atom,

\section{Electron affinity}

Energy released to

the atom,

Ea

\section{Bond character}

Character of the bond in the compound

related to the electronegativity difference between the atoms involved in bond (ionic, covalent)

Main group Transition Main group Transition Main group Transition Main group Transition Main group Transition Main group Transition elements metals elements metals elements metals elements metals elements metals elements metals

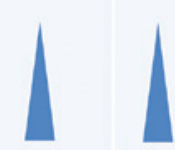

Elemental volatility

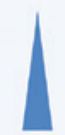

Compound volatility

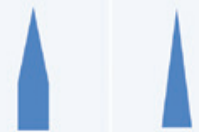

Electronegativity

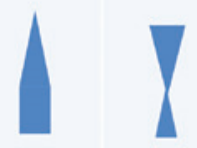

Thermodynamic stability

Energy to transfer the Energy to transfer the Parameter relevant for Formation enthalpy The property of oxide The tendency to form element from solid compound from its solid the polarity of the highest oxidation species in reaction with metallic lattice instead state into its gaseous chemical bonds in the state compounds out atomic state state $\Delta \mathrm{H}^{*}$

$\Delta \mathrm{Hsubl}$ compounds, of the elemental constituents, $\chi$ $\Delta \mathrm{fH}^{0}$ water

ion cov ion cov
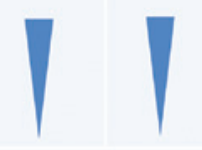
pKa, pkb

Main group Transition Main group Transition Main group Transition Main group Transition Main group Transition Main group Transition elements metals elements metals elements metals elements metals elements metals elements metals

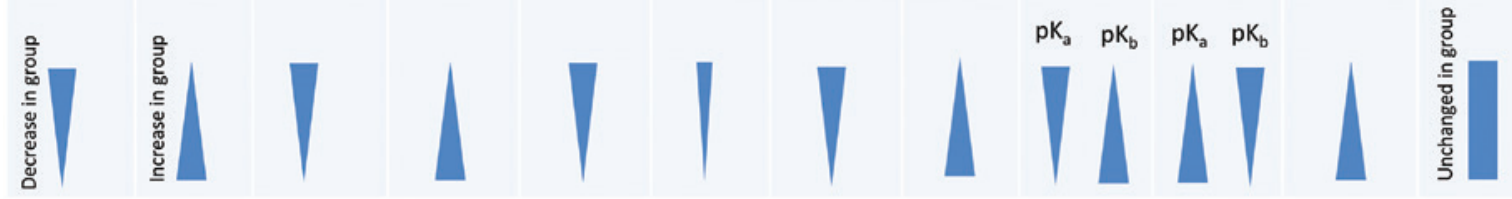

Figure 2: Definitions of some properties of elements in the periodic table and of their compounds relevant to transactinide chemistry. Typical trends of properties along the groups (with increasing Z) of main group elements (groups: 1-2, 13-18) and transition metals (groups: 3-12) are indicated. 
states is highest but it decreases along the group. Along the members of main groups 1, 2, 13-17, e. g. an increasing metallic character or a decreasing acidic character of their oxides is observed.

\section{The chemical investigation of transactinides}

\subsection{Relativity in TA chemistry}

Generally, the electronic configurations determine the chemical properties of the elements. This electronic structure is more and more influenced by the high electrostatic fields induced by the large nuclear charges (Z) of the heaviest atoms. Strong Coulomb fields force the electrons with zero angular momentum ( $\mathrm{s}$ and $\mathrm{p}_{1 / 2}$ ) in close vicinity of the nucleus to speed up to velocities of substantial fractions of the speed of light. This has the primary relativistic consequence of increasing mass and thus of a stronger binding of the corresponding electrons in the atom. These electron orbitals contract as a consequence of the primary relativistic effect and thus increasingly shield the nuclear charge against the other electrons. Thus, the other orbitals, with higher angular momentum $\left(\mathrm{p}_{3 / 2}, \mathrm{~d}\right.$, and $\left.\mathrm{f}\right)$ observe a lower effective nuclear charge and become thus more diffuse and less bound. Additionally the spin-orbit coupling leads to an energetic split of orbitals with different angular momenta, seen as the third relativistic effect [4, 5] (see for review [6, 7]). The pictorial representations of electron orbitals by White in $1931[8,9]$ reveal impressively how relativistic effects lead to strong changes in orbital geometry, electron density, and binding energy, when describing the electronic structure of atoms according to Dirac's combination of Schrödinger's quantum mechanics with Einstein's principles of relativity, which was accomplished just 2 years earlier in 1929 [10]. Most obvious is the geometric change of the $\mathrm{p}_{1 / 2}$ orbital, which becomes spherical and contracted by the primary relativistic effect. Only much later, the relativistic effects were accounted for observations of particular chemical properties of heavier elements such as lanthanides, gold, mercury, thallium, or lead [4]. Known trends of properties as observed in the groups and rows of the periodic table contain basically the principles of relativity already, but the increase of this influence along the group is not expected to be linear. The general expectation is that relativistic effects shall scale roughly with the square of the atomic charge (Z2) [7]. Hence, the most prominent influence on chemical properties is predicted for SHE. Mutual correlation of thermodynamic state functions can help to linearize trends in the periodic table since state functions are all influenced by relativistic effects. Thus, predictions can be made by extrapolation from these trends. However, this requires at least the prediction or the experimental result for one of the thermodynamic state functions used. In an increasing number of cases predictions of single atomic behavior or macroscopic properties can be derived using modern relativistic density functional theory (see for review [11, 12]). Those predictions perpetually improve, well correlated to the availability of computing power, but also due to excellent methodical developments. Nowadays, even solid state calculations appear possible for SHE $[13,14]$.

\subsection{The production of TA}

Lacking their occurrence in nature [15], the superheavy elements are produced artificially in heavy-ion induced nuclear fusion reactions (see for review [16, 17]). The involved nuclear processes are not topic here. Briefly, the most important features of this production path relevant for the subsequent chemical studies are:

- The complete nuclear fusion process of heavy ions with the irradiated target atoms is an exceptionally rare process leading to production rates of transactinides in the range from several atoms per minute up to single atoms per several days [18];

- The SHE production is accompanied by the production of partial fusion products, in so-called multi-nucleon transfer reactions, occurring at orders of magnitude higher rates [19], which produce isotopes of elements of almost the entire periodic table, some of which might interfere with the detection of the transactinide products and have to be separated.

- The produced single atoms of TA elements recoil out of the production target with the momentum of the incoming beam particles. Therefore, the solid irradiation targets have to be thin enough for the heavy atoms to leave the material [20,21].

- The half-lives of the produced TA isotopes known today range from milliseconds up to several seconds only, rarely to minutes and hours (see Figure 3) and compilation [22].

\subsection{From production to chemistry}

Typically, for chemistry experiments the products recoiling out of the thin production target are thermalized in a 


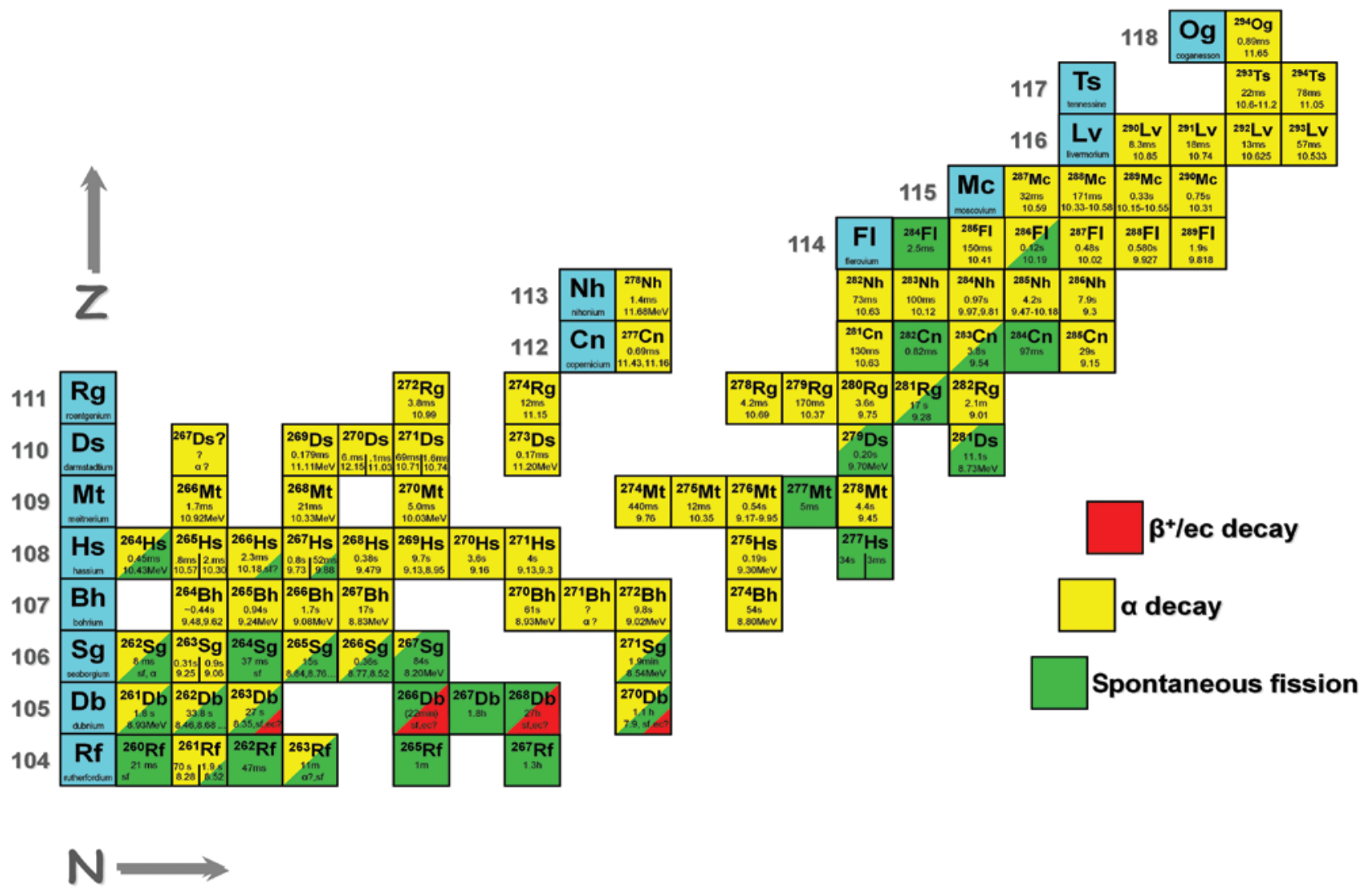

Figure 3: Chart of SHE nuclides, half-lives and predominant decay modes are indicated.

Data and color scheme adopted from [22].

transport gas, and, if volatile enough, are transported in the gas phase to the laboratory. This principle allows for a first-stage in situ separation of non-volatile by-products of the nuclear fusion reaction already during this transport. In the case of low volatility of the products many small solid particles are admixed to the stopping gas forming an aerosol gas-jet [23]. There, the products are preferentially adsorbed on the large surface area of the small (diameter $100 \mathrm{~nm})$ and abundant $\left(\sim 10^{7} / \mathrm{cm}^{3}\right)$ particles and are thus transported to the laboratory together with the majority of the by-products. The choice of aerosol material can be adjusted to the needs of the chemistry e. g.: $\mathrm{KCl}$ salt particles are used for studies in the aqueous phase because of their easy dissolution in water, or $\mathrm{C}$ particles are preferentially applied for gas phase chemical experiments in chlorinating and oxidizing atmospheres, where they are burnt to non-interfering gaseous products. In more recent experiments, between the target and the recoil stopping chamber a magnetic or electrostatic recoil separator serves depending on the configuration as energy, momentum, or velocity separator distinguishing the SHE products from unwanted by-products mainly produced in multi-nucleon transfer reactions mentioned above [24]. The advantage of this experimental scheme is the cleanliness of the product due to pre-separation and the removal of the heavy ion beam, which otherwise prevents the investigation of fragile volatile chemical compounds or destroys aerosol particles used for the transport of non-volatile products.

\subsection{Chemical methods}

The chemical character of an element is classically inferred by revealing its partake in chemical reactions which might be reversible or irreversible. Having at hand large quantities of one element single step chemical reactions offer the possibility to determine concentrations of the involved species in their corresponding chemical states, which they may have populated in the studied chemical reaction. If reversible reactions are investigated, e.g. at varied temperatures, equilibrium thermodynamic evaluations allow for the determination of thermochemical data from mass action laws. However, chemical investigations of transactinides are performed at one atom at a time scale. Therefore, the single atoms have to be offered the possibility to change between their chemical states in the reaction 
of interest multiple times within their short life times. The thermochemical equilibrium of reversible reactions can be described then by a mass action law just replacing the classical concentrations by probabilities to observe the single atom in one or the other available chemical state [25]. Hence fast multistage chromatographic methods are the methods of choice to chemically characterize single atomic TA:

- Chemical gas-phase adsorption chromatographic investigations are investigating the formation of certain stable volatile chemical states (element, compound, complex etc.) and their multiple reversible adsorption chromatographic interaction with inert stationary surfaces such as quartz, alumina, or with metals. The results from such experiments reveal the general observation of the formation of volatile compounds and their standard adsorption enthalpies $\left(\Delta \mathrm{H}_{\text {ads }}\right)$ on the investigated stationary phases [26].

- Aqueous phase investigations comprise the multiple chromatographic interaction of a charged or uncharged complex compound in aqueous solutions with stationary phases, like ion exchange resins, extraction resins, or secondary mobile organic extraction phases, such as immiscible organic solvents with densities different from water. The final results reveal the charge state of the complex (number of ligands) and the distribution coefficient $\left(\mathrm{K}_{\mathrm{d}}\right)$ of the respective complex between the mobile and stationary phase [27].

The results of the chemical investigations with transactinides and with their lighter homologues based both on single atomic experiments can be directly compared, because polyatomic compounds with more than one central atom per molecule are excluded. Otherwise, to compare results to general trends established among properties of macroscopic amounts of the corresponding homologues and other elements, the single atomic behavior of the well-accessible homologues and compounds can be empirically correlated to their macroscopic properties [28]. To derive such correlations, single atomic experiments have to be performed with a large number of known elements in the same or similar chemical system and then correlated to known chemical properties of their macroscopic solid or gaseous states (see e. g. Figure 4). Vice versa, the single atomic or single molecular behavior can be predicted from such correlations by extrapolating trends in properties established by the periodic table, e. g. the predicted sublimation enthalpy of an unknown chloride can be translated into the microscopic adsorption enthalpy on a quartz surface using Figure 4, thus, enabling the design of a suitable confirmation experiment.

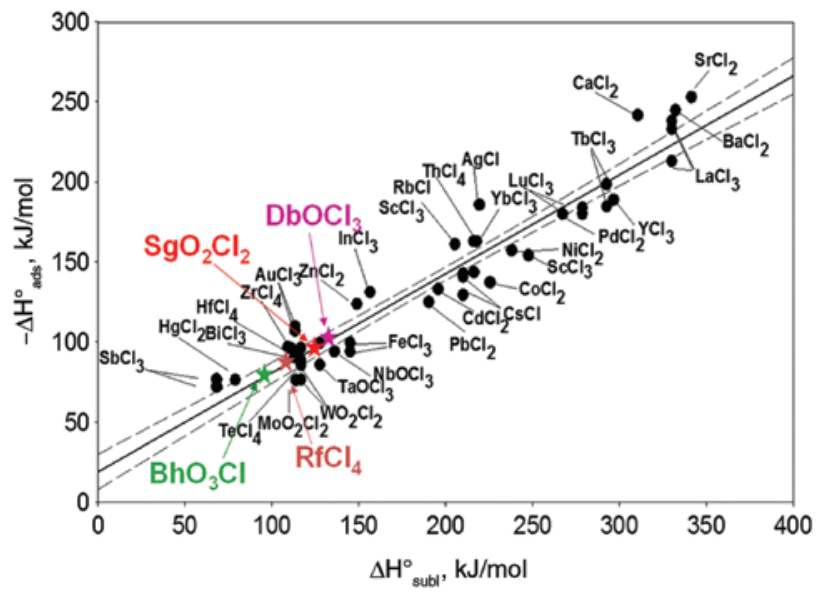

Figure 4: Empirical correlation of the microscopic single molecular property standard adsorption enthalpy $\Delta \mathrm{H}^{\circ}{ }_{\text {ads }}$ on a quartz surface at chlorinating conditions using $\mathrm{HCl} / \mathrm{O}_{2}$ or $\mathrm{Cl}_{2} / \mathrm{SO}_{2} \mathrm{Cl}_{2}$ ) and the macroscopic property related to volatility of the compound the standard sublimation enthalpy $\Delta \mathrm{H}^{\circ}{ }_{\text {subl }}$.

The adsorption data were obtained in isothermal gas chromatography experiments or thermochromatography experiments with carrier free amounts of the corresponding elements. Results obtained from gas phase adsorption chemical experiments with transition metal TA are indicated (figure adapted from [29]).

\section{Experimental results with SHE}

\subsection{Transition metals (d-elements) groups 4-8}

\subsubsection{Rutherfordium and dubnium}

The start of gas phase chemical investigations of transactinides dates back to 1966 when Zvara and co-workers published results of a first ever gas phase chemical study of $\mathrm{RfCl}_{4}$ [30]. By that time the actinide concept [31] was well accepted and the periodic table suggested the element with the atomic number 104 to be placed into group 4 together with the elements titanium, zirconium, and hafnium. Element 105 should be similar to vanadium, niobium, and tantalum in group 5. Thus these homologues of the transactinide elements have been investigated thoroughly at identical chemical conditions in preparation of the transactinide experiments ([26] and references therein). For groups 4 and 5 elements the formation of stable volatile tetra-halides and oxohalides of highest oxidation state + IV and pentahalides or oxohalides of highest oxidation state $+\mathrm{V}$ are expected, respectively. Their stability should increase along the corresponding groups and their volatility is expected to decrease (see Figure 2). This purely 
periodic-table-based expectations were the primary reason to investigate $\mathrm{Rf}$ and $\mathrm{Db}$ in the chlorinating and brominating systems expecting the formation of highest oxidation states in the gas phase (for review see $[12,26]$ ). Main difficulties arose in these experiments from the observed formation of several chemical states such as $\mathrm{MOX}_{2}$ and $\mathrm{MX}_{4}$, as well as $\mathrm{MO}_{3} \mathrm{X}$ or $\mathrm{MOX}_{3}$ and $\mathrm{MX}_{5}$ for groups 4 and 5 elements, respectively $(\mathrm{X}=\mathrm{Cl}, \mathrm{Br})$. These early experiments failed to investigate the transactinide simultaneously with a lighter homologue in the same experiment. Thus, the direct comparison of the observed properties was difficult. Slight deviations from trends expected by the periodic table cannot be excluded, but also transport reactions have to be considered in the discussion of the achieved data, e.g. [32]. More experimental data is certainly needed to firmly conclude on the halide chemistry of Rf and $\mathrm{Db}$ and on the trends in the corresponding groups.

\subsubsection{Seaborgium and bohrium}

In the late 1980s and during the 1990s a revival of the transactinide gas phase chemistry occurred due to the development of accelerator technology and of the fast gas chromatography methods based on the On-Line Gas chromatography Apparatus (OLGA) technique [33, 34]. Furthermore, the availability of intense ${ }^{22} \mathrm{Ne}$ ion beams at various accelerators world-wide and the availability of stable irradiation targets prepared out of ${ }^{248} \mathrm{Cm}$ and ${ }^{249} \mathrm{Bk}$ [20] turned out to be very advantageous. In 1996 and 1999 first chemical characterizations of elements seaborgium [35-39] and bohrium [40] revealed their close resemblance to elements in groups 6 and 7 of the periodic table, respectively. They were investigated in the chemical form of $\mathrm{SgOCl}_{4}$ or $\mathrm{SgO}_{2} \mathrm{Cl}_{2}$ and $\mathrm{BhO}_{3} \mathrm{Cl}$. Based on predictions by trends in the groups 6 and 7 of the periodic table, respectively, those oxychlorides in the highest oxidation states of the two elements were presumable the most stable ones formed at high temperatures under chlorinating conditions using $\mathrm{Cl}_{2} / \mathrm{SO}_{2} \mathrm{Cl}_{2}$ and $\mathrm{HCl} / \mathrm{O}_{2}$ gas phases and high temperatures up to $1000{ }^{\circ} \mathrm{C}$. Their adsorption interaction strength on quartz surfaces were quantified in isothermal gas chromatography experiments and translated into thermodynamic state functions [28, 29] (see Figures 3 and 4). These results nicely follow the trends expected by the periodic table (Figures 4 and 5). The results from the model experiments with Mo, W, Tc, and Re ([12, 26] and references therein) as well as their simultaneous study together with the SHE in the same experiment were instrumental to prepare the experiments and to allow a conclusive chemical data analysis.

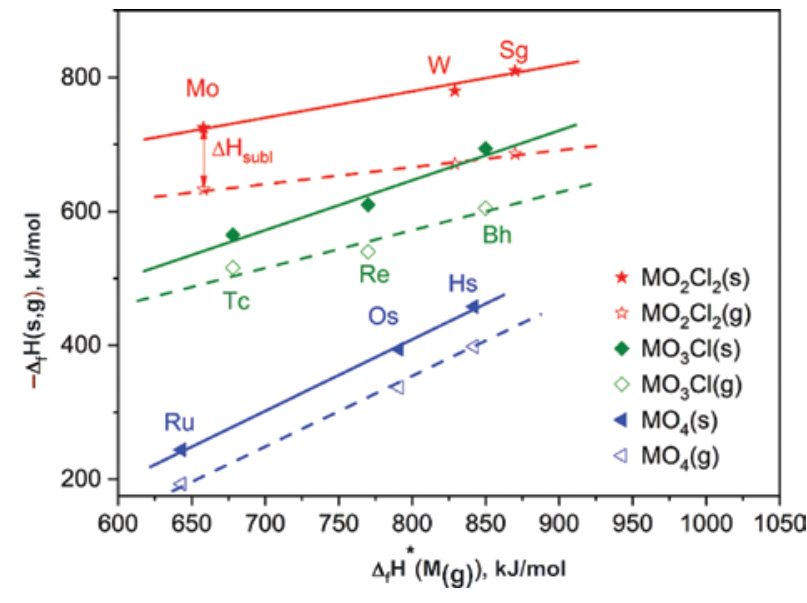

Figure 5: The mutual correlation of thermodynamic state functions for transition metal compounds in highest oxidation states: thermodynamic stabilities $-\Delta_{\mathrm{f}} \mathrm{H}(\mathrm{s}, \mathrm{g})$ of the highest oxidation state compounds of groups $6-8$ are plotted against the atomic formation enthalpies $-\Delta_{\mathrm{f}} \mathrm{H}(\mathrm{M}(\mathrm{g}))$ of the elements.

The lines are shown to guide the eye and to reveal the trends in the groups. The distance between the open and the filled symbols of one corresponding compound class of one group reveals the standard sublimation enthalpies $\Delta \mathrm{H}_{\text {subl }}$ (indicated as an example as red arrow for $\mathrm{MoO}_{2} \mathrm{Cl}_{2}$ ). The decreasing trends of the volatility (increasing $\Delta \mathrm{H}_{\text {subl }}$ ) confirming the expectations of the periodic table can be seen particularly well in groups 6 and 7 .

\subsubsection{Hassium}

The particularly high volatility and stability of tetroxides of group 8 elements of the periodic table triggered the investigation of hassium in this chemical system [41]. Model experiments with the lighter homologues $\mathrm{Ru}$ and particularly Os were very important for the preparation of these experiments [42]. The development of an on-line thermochromatography approach pioneered at the Lawrence Berkeley National Laboratory, USA [43] permitted the investigation of the adsorption interaction in situ on the surfaces of the silicon-based detectors allowed for an unprecedented efficiency increase confronting the decrease in production rate when using the ${ }^{26} \mathrm{Mg}$ on ${ }^{248} \mathrm{Cm}$ fusion reaction compared to ${ }^{22} \mathrm{Ne}$ induced reactions. The hassium tetraoxide could be formed in situ in oxygen containing gas within the recoil chamber behind the rotating curium oxide target (ARTESIA) [44]. Its adsorption interaction was studied using the thermochromatography device Cryo On-Line Detector (COLD) [45]. From the determined adsorption strength of the tetroxides on the detector surface a macroscopic volatility could be deduced empirically. Thus thermodynamic state functions became accessible [28] (see Figure 5). In group 8 the molecular polarizability dominates the weak binding in the solid state. Thus, for 
the symmetric $\mathrm{MO}_{4}$ molecules the differences between the volatilities of these compounds are small among the group 8 members. This was also confirmed by relativistic density functional calculations combined to a physisorption model based on London forces [46].

\subsubsection{High oxidation states of transition metals}

In most of the chemical studies of the transition element series a general similarity of the transactinide to the corresponding homologous elements of the same groups was observed for Rf-Hs. Trends in the formation enthalpies and volatilities were deduced empirically (see e. g. Figure 5). The general trends of the increasing stability of the compounds with highest oxidation states and decreasing volatilities along the groups as expected by the periodic table were mainly preserved.

\subsubsection{Gas phase carbonyl complexes of transition metals}

The recent observation of gas phase carbonyl complexes formed in situ from single atoms of group 6-9 elements if thermalized in CO containing atmospheres lead to an increased investigation of these complex compounds, e. g. $[47,48]$. The observed volatility of the formed complex compounds similar to the symmetric tetroxides of group 8 elements allowed for the use of cryo-thermochromatography detectors to identify the formation and subsequently the adsorption of these species on inert silica surfaces. Physical preseparation was indispensable for the survival of the fragile gas phase molecules, due to a complete heavy ion beam removal from the location where the chemical reactions occur. The first TA experiments showed a clear resemblance of $\mathrm{Sg}(\mathrm{CO})_{6}$ to the lighter homologous compounds $\mathrm{Mo}(\mathrm{CO})_{6}$ and $\mathrm{W}(\mathrm{CO})_{6}$ [49]. Also in this adsorption interaction the molecular polarizability dominates the adsorption bond to the surface. Thus, for the symmetric $\mathrm{M}(\mathrm{CO})_{6}$ molecules the adsorption enthalpy differences are small, an expectation which was bolstered by relativistic density functional calculations [50].

Further experiments are under way to investigate for the first time the bond stability in a transactinide compound directly. Exceptionally, this bond features a zero oxidation state central atom and a sigma-donor- $\pi$-acceptor bond of the CO ligands. The first CO-bond dissociation energy is a relevant stability parameter and assessable experimentally through a thermal decomposition of the carbonyls on an inert silver surface $[51,52]$ as well as theoretically by density functional theory $[53,54]$ (see Figure 6).
The trend in the periodic table would suggest an increasing stability of the carbonyl bond along the group from Mo over $\mathrm{W}$ to Sg, i. e. an increasing decomposition temperature.

\section{$4.2 \mathrm{~s}$-Elements of group 12}

The specialty of elements of group 12: zink, cadmium, and mercury is quite obvious. These elements are not typical transition metals and also the trends in along this group are not typical for transition metal groups. The electronic structure consists of a filled inner d-shell and a closed outer s-valence shell. The outer valence electrons dominate the chemical behavior of these elements which show up in compounds mostly in oxidation state $\mathrm{II}+$. The heavier member of this group Hg is surprisingly different. It appears in liquid state at standard conditions, it is chemically quite inert and it forms $\mathrm{Hg}_{2}{ }^{2+}$ ions in oxidation state I+ with an intermetallic bond in some of its chemical compounds, e. g. $\mathrm{Hg}_{2} \mathrm{Cl}_{2}$ (calomel). These properties are attributed to relativistic effects [4, 7]. According to the increasing trend of inertness or nobility, which can be also quantified as ionization potential ( $\left.\mathrm{I}_{\mathrm{p}}\right)$, copernicium is expected to be the element in this group most stable in its elemental state. The trend of increasing elemental volatility in group 12 of the periodic table points towards a very volatile copernicium [56]. It was suggested in 1981 to investigate gas phase adsorption for copernicium on noble

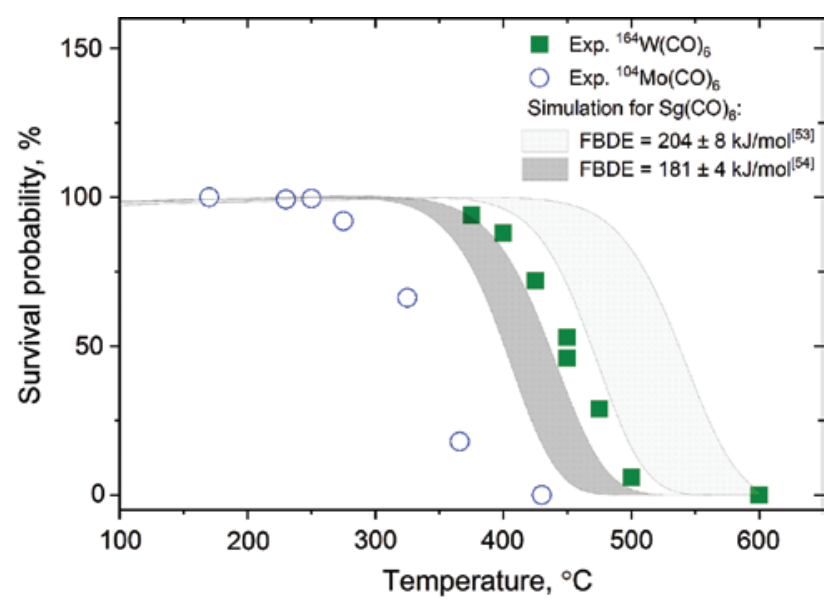

Figure 6: The experimentally determined probability for carbonyl compounds of group 6 elements $\mathrm{Mo}(\mathrm{CO})_{6}$ (blue open symbols, $\mathrm{FBDE}=169 \mathrm{~kJ} / \mathrm{mol}$ [55]) and $\mathrm{W}(\mathrm{CO})_{6}$ (green closed squares, $\mathrm{FBDE}=192 \mathrm{~kJ} / \mathrm{mol}$ [55]) to survive the thermal contact with a silver surface held at varied temperatures.

Predictions for the first $\mathrm{CO}$ bond dissociation enthalpy of $\mathrm{Sg}(\mathrm{CO})_{6}$ available from relativistic density functional theory were translated into an experimental expectation using a model developed in [52]. These are shown as shaded areas. 
metal surfaces [57]. The formulated expectation was that the intermetallic interaction could be easily distinguished from a physisorption interaction to reveal true metallic chemical character. Model experiments with mercury and radon $[58,59]$ were crucial in preparation of the experiments using cryo-thermochromatography with gold-covered silicon detectors as chromatographic surface. Twenty five years after the suggestion of the experimental principle two experimental campaigns performed at the Flerov Laboratory of Nuclear Reactions, Dubna, Russia revealed the first adsorption data for copernicium on a gold surface $[60,61]$. The experiments were performed using the nuclear fusion of ${ }^{48} \mathrm{Ca}$ with ${ }^{242,244} \mathrm{Pu}$; $\mathrm{Cn}$ being a decay product of the primarily produced short-lived isotopes of flerovium. A tiny natural $\mathrm{Nd}$ admixture to the target allowed producing ${ }^{182-185} \mathrm{Hg}$ simultaneously. Short-lived ${ }^{219-220} \mathrm{Rn}$ isotopes were also produced simultaneously in nuclear transfer reactions. Thus, without pre-separation, the investigation of ${ }^{182-185} \mathrm{Hg}$ and ${ }^{219} \mathrm{Rn}$ together with the ${ }^{283} \mathrm{Cn}$ was possible in the same experiment. The observed weak adsorption of copernicium on gold revealed its increased inertness. This observation was later confirmed and the deduced adsorption enthalpy was empirically correlated to the macroscopic volatility [61]. As shown in Figure 7, the result confirmed the predictions from the periodic table. A noble gas-like behavior as suggested in 1975 [62] could be ruled out, though. Metallic properties still dominate the interaction of copernicium with noble metals in agreement with predictions from density functional theory (see [63] and references therein).

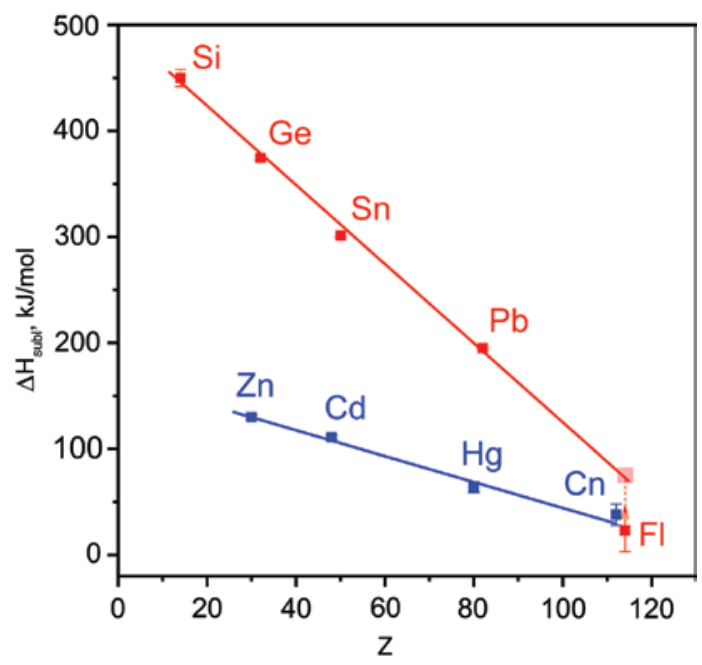

Figure 7: The elemental volatility of elements in group 12 (blue) and 14 (red): standard enthalpies of sublimation $\left(\Delta \mathrm{H}_{\text {subl }}\right)$ are plotted against the atomic number $\mathrm{Z}$.

Trends suggested by the periodic table are indicated as colored lines to guide the eye.

\section{3 p-Elements of groups 13 and 14}

The trends in groups 13 and 14 of the periodic table predict increasing metallic character along the groups, increasing stability of the lower oxidation states, and increasing stability of the elemental states. The latter two trends express the primary relativistic effect leading to the stabilization of the valence electrons in the $s$ and $p_{1 / 2}$ orbitals. Thus, in first chemical experiments the volatility of the atomic states and their adsorption properties on gold surfaces were in the focus of investigations of both elements. The method of cryo-thermochromatography is again the method of choice due to its high efficiency.

The first experiments with nihonium were thoroughly prepared by model experiments with its homologues in group 13, In and Tl $[64,65]$. A strong and reproducible formation of the molecule TlOH was observed in a broad range of experimental conditions in contact with quartz. The interaction of $\mathrm{TlOH}$ with quartz is comparably strong as the interaction of the elemental state with this surface. This translates into a similar macroscopic volatility for $\mathrm{Tl}$ and $\mathrm{TlOH}$, which is also deduced from recent relativistic calculations $[63,66]$. Therefore, it appears difficult to distinguish these chemical states also for Nh. In first experiments nihonium $(\mathrm{Nh})$ was produced in the ${ }^{48} \mathrm{Ca}$ induced nuclear fusion reaction with ${ }^{243} \mathrm{Am}$ as an alpha decay product of the primary fusion product moscovium (Mc). For these investigations, the produced ${ }^{284,285} \mathrm{Nh}$ isotopes were thermalized and transported in an inert gas phase through a quartz wool filter and through a 4-m long Teflon capillary to an isothermal detector made out of silicon detectors covered with thin layers of gold. A transport of ${ }^{284} \mathrm{Nh}$ was observed through the Teflon capillary a deposition at room temperature on the gold-covered detector surfaces. This approach did not allow for an unambiguous chemical speciation. Thus, a weak interaction of the formed Nh species with Teflon surfaces was stated and a stronger interaction with gold [67]. Later, a second experiment with preseparation and no quartz surfaces in contact with the nuclear fusion reaction products did not reproduce the observation of a volatile nihonium species at much cleaner conditions, which indicates the formation of a volatile molecule in the initial experiment [68]. Adsorption enthalpy limits on gold $(<-60 \mathrm{~kJ} / \mathrm{mol})[67]$ and Teflon $(<-45 \mathrm{~kJ} / \mathrm{mol})[68]$ could be estimated from these experiments, however again, with an unknown chemical speciation of nihonium. Further experiments with $\mathrm{Tl}$ are under way to force the stable formation of one particular volatile molecular species using oxygen and water containing atmospheres and quartz surfaces in experiments using the advantages of preseparation. 
The first results obtained with flerovium [69], which was simultaneously studied with coperniciun (see above) revealed its weak adsorption on the gold surface and thus confirmed a strong stabilization of its elemental atomic state. These results were generally confirmed in a second series of experiments showing however a stronger adsorption on gold [70]. An exceptionally high volatility can be deduced from the observed adsorption on gold based on the empirical correlation of adsorption data to volatility, which was used here similarly to the estimations for copernicium [61]. This would confirm the early predictions for element 114 [62] and from recent relativistic density functional solid state calculations [13]. Moreover, the experimentally deduced value reveals a significant deviation from the expected trend in the periodic table towards higher volatility or lower sublimation enthalpy (see Figure 7).

\section{Prospects in TA chemistry}

With the exception of the carbonyl compounds for the transition metals of groups 4-8 so far only compounds in highest oxidation states have been investigated. Lower oxidation states in gas phase and liquid phase might reveal the relativistic effects more strongly. The access to Rf, $\mathrm{Db}$, and $\mathrm{Sg}$ in atoms per minutes to atoms per hours quantities allows for unprecedented significance of chemical investigations. New heavier isotopes of these elements with half-lives in the order of tens of minutes and even several hours have been observed in decay chains of higher-Z elements (see Figure 3). Although, they appear not as readily accessible as the directly produced ones, their existence allows chemists for dreaming-up experiments involving more complex chemical investigation schemes with a better defined chemical speciation. For the elements of groups 6-9 the formation and speciation of volatile carbonyl complexes opens exciting prospects for transport and chemical and physical investigations of elements seaborgium, bohrium, hassium, and for the first time also of meitnerium, which is supposed to form carbonyls such as $\mathrm{Mt}(\mathrm{CO})_{4}$, similar to its lighter homologue iridium. The noble metal elements of groups 7-11 are clearly predestinated for electrochemical investigation schemes. For those groups predictions of the redox potentials are available from trends in the periodic table and from density functional theory ([71] and references therein). First steps towards electrochemical investigations have been made [72-74].
For the superheavy elements of groups 12-14 further experiments are required at highest statistical significance to prove the very preliminary conclusions drawn here. Other stationary phases for chromatography experiments are under evaluation. Chalcogenides are very stable compounds in both group 12 and 14 . The investigation of these formation reactions might reveal the metallic character of both elements and show more pronounced relativistic effects [75].

Within the groups 15-17 an increase of the metallic character is anticipated [56]. This can be nicely shown by empirically correlating the first ionization potential $\left(\mathrm{I}_{\mathrm{p}}\right)$ with the electron affinity (see Figure 8). All results of most modern and accurate ab initio predictions for superheavy transactinides [76] shift them into the area of metals. The low ionization potentials of $\mathrm{Nh}, \mathrm{Lv}$, and Mc might allow for a direct measurement of $\mathrm{I}_{\mathrm{p}}$ using surface ionization techniques currently in use for the heavy actinides [77]. The reasonable volatility combined with a metallic character expected for the superheavy elements 12-18 will enable their investigation by gas chromatographic techniques. Vacuum chromatography [59, 78] and low pressure chromatography behind buffer gas RF stopping cells [79] will allow for a speed increase to reach the milliseconds time domain as required by the short half-lives of Mc, Lv, Ts, and Og (see Figure 3).

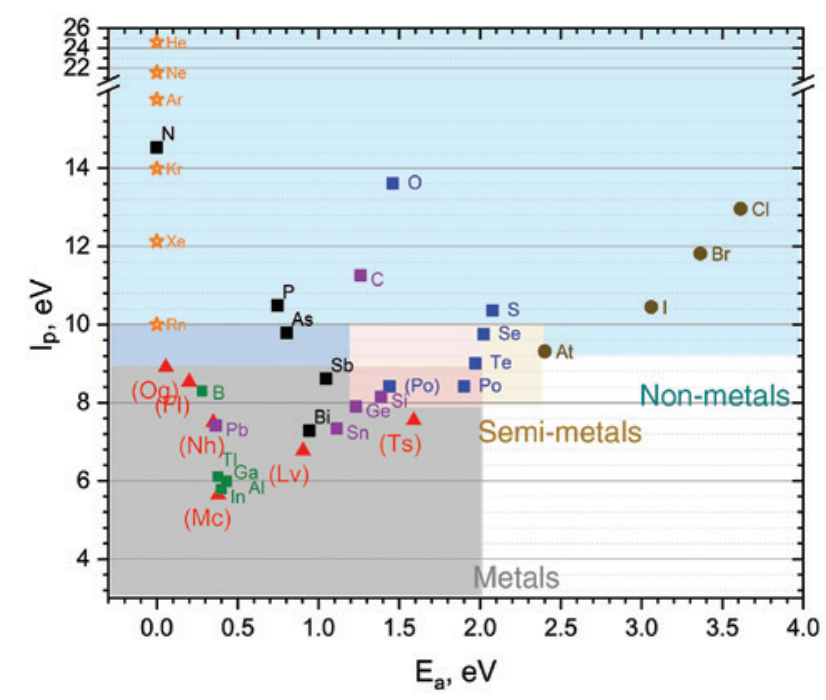

Figure 8: Correlation between the atomic properties ionization potential $\left(I_{p}\right)$ and electron affinity $\left(E_{a}\right)$.

These properties divide main group elements into metals, semimetals, and non-metals. Predictions for the corresponding transactinide elements ([74] and references therein) are shown in red, indicating a metallic behavior as also expected by the periodic table. Ts is very close to semi metals. $\mathrm{Fl}$ and $\mathrm{Og}$ are on the border between metals and inert gases. 


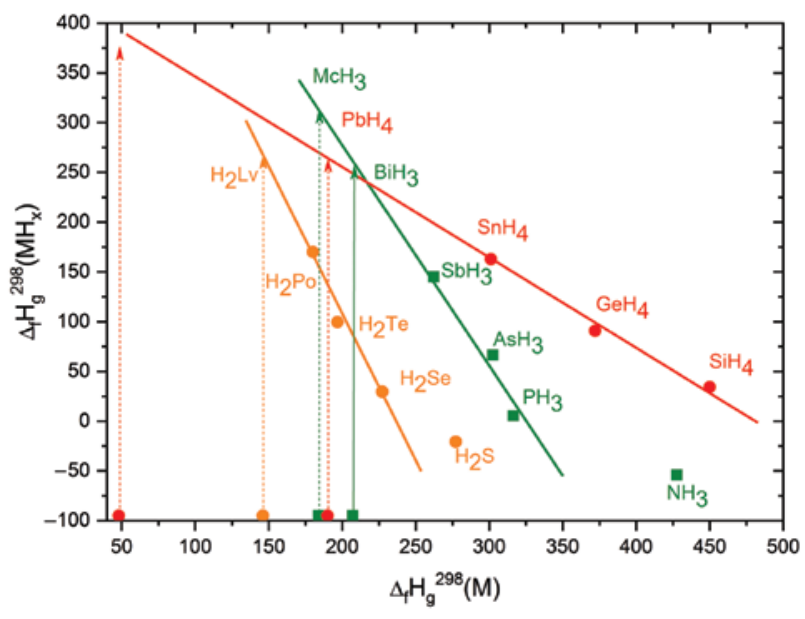

Figure 9: Mutual correlation of thermodynamic state functions: the standard formation enthalpy of gaseous hydrides from the elements correlated with the standard atomic formation enthalpies of the elements.

Thus trends in the stability in the main groups of the periodic table are linearized and extrapolations are possible having predictions for the volatility of the elements at hand (e. g. from [56]).

Furthermore, the availability of stability data for hydride compounds of the elements of groups 14-17 allows to predict the trends of stability in these groups (see e.g. Figure 9). The observation of $\mathrm{BiH}_{3}$ and $\mathrm{PoH}_{2}$ formed from the atomic states of these elements with atomic hydrogen suggests this chemical system to study low oxidation state compounds of Mc and Lv, too. This holds true also for the group 17 elements, including Ts, not shown here.

The atomic structure understanding is challenged by recent calculations for the element oganesson [80], which appears to be in the low right corner of the current periodic table, where two of the above mentioned exciting edges are crossing. The high precision prediction of a small electron affinity for the superheavy noble gas $\mathrm{Og}$ $[81,82]$ reveals current theoretical possibilities and guides towards future experimental tasks.

\section{Conclusion}

So far only scarce experimental data are available for selected transactinide elements. The entire spectrum of results can be seen in the light of the periodic table of the elements, which appears once again as a powerful tool to predict properties of unknown elements. The step towards the investigation of superheavy elements at highest statistical significance is important to further reveal relativistic effects in their electronic structure. The current investments into accelerator and separator technology and into related infrastructure world-wide are considered not only a major contribution, but also a strong commitment to further investigate physics and chemistry of the transactinide elements. Theory and experiment have to work hand in hand to tackle these demanding challenges. The periodic table will provide further guidance in this endeavor. Since long, the periodic table is under construction beyond the currently known transactinides. Major difficulties arise from the appearance of new inner electron shells, currently not yet understood completely [83-85], and challenge the prediction of chemical properties for elements beyond element 121.

\section{References}

1. Mendeleev, D. I.: Relationship of elements properties to their atomic weights. J. Russ. Chem. Soc. 1, 60 (1869) (in Russian).

2. Mendeleev, D. I.: On the relations of elements properties to their atomic weights. Z. für Chem. 12, 405 (1869) (in German).

3. Geng, H. Y.: Public debate on metallic hydrogen to boost high pressure research. Mat. Rad. Extr. 2, 275 (2017).

4. Pyykkö, P., Desclaux, J.-P.: Relativity and the periodic system of elements. Acc. Chem. Res. 12, 276 (1979).

5. Fricke, B., Waber, J. T.: Theoretical prediction of the chemistry of superheavy elements. Actinides Rev. 1, 433 (1971).

6. Schwerdtfeger, P., ed.: Relativistic Electronic Structure Theory. Part I. Fundamentals; Theoretical and Computational Chemistry (2002), Vol. 11, Elsevier, Amsterdam.

7. Pyykkö, P.: Relativistic effects in structural chemistry. Chem. Rev. 88, 563 (1988).

8. White, H. E.: Pictorial representations of the electron cloud for hydrogen-like atoms. Phys. Rev. 37, 1416 (1931).

9. White, H. E.: Pictorial representations of the Dirac electron cloud for hydrogen-like atoms. Phys. Rev. 38, 513 (1931).

10. Dirac, P. A. M.: Quantum mechanics of many-electron systems. Proc. R. Soc. Lond. A 123, 714 (1929).

11. Pershina, V. P.: Electronic structure and properties of the transactinides and their compounds. Chem. Rev. 96(6), 1977 (1996).

12. Türler, A., Pershina, V.: Advances in the production and chemistry of the heaviest elements. Chem. Rev. 113, 1237 (2013).

13. Herrmann, A., Furthmüller, J., Gäggeler, H. W., Schwerdtfeger, P.: Spin-orbit effects in structural and electronic properties for the solid state of the group-14 elements from carbon to superheavy element 114. Phys. Rev. B 82, 155116 (2010).

14. Steenbergen, K. G., Mewes, J.-M., Pasteka, L. F., Gäggeler, H. W., Kresse, G., Pahl, E., Schwerdtfeger, P.: The cohesive energy of superheavy element copernicium determined from accurate relativistic coupled-cluster theory. Phys. Chem. Chem. Phys. 19, 32286 (2017).

15. Ter-Akopian, G. M., Dmitriev, S. N.: Searches for superheavy elements in nature: cosmic-ray nuclei; spontaneous fission. Nucl. Phys. A 944, 177 (2015).

16. Hofmann, S., Münzenberg, G.: The discovery of the heaviest elements. Rev. Mod. Phys. 72(3), 733 (2000). 
17. Oganessian, Yu. Ts., Utyonkov, V. K.: Superheavy nuclei from ${ }^{48} \mathrm{Ca}$-induced reactions. Nucl. Phys. A 944, 62 (2015).

18. Zagrebaev, V. I., Greiner, W.: Cross sections for the production of superheavy nuclei. Nucl. Phys. A 944, 257 (2015).

19. Kratz, J. V., Loveland, W., Moody, K. J.: Syntheses of transuranium isotopes with atomic numbers $Z \leq 103$ in multi-nucleon transfer reactions. Nucl. Phys. A 944, 117 (2015).

20. Roberto, J. B., Alexander, C. W., Boll, R. A., Burns, J. D., Ezold, J. G., Felker, L. K., Hogle, S. L., Rykaczewski, K. P.: Actinide targets for the synthesis of super-heavy elements. Nucl. Phys. A 944, 99 (2015).

21. Runke, J., Düllamnn, Ch. E., Eberhardt, K., Ellison, P. A., Gregorich, K. E., Hofmann, S., Jäger, E., Kindler, B., Kratz, J. V., Krier, J., Lommel, B., Nitsche, H., Roberto, J. B., Rykaczewski, K. P., Schädel, M., Thörle-Pospiech, P., Trautmann, N., Yakushev, A.: Preparation of actinide targets for the synthesis of the heaviest elements. J. Radioanal. Nucl. Chem. 299(2), 1081 (2014).

22. Magill, J., Dreher, R., Soti, Z.: The Karlsruhe Chart of Nuclides (2018). $10^{\text {th }}$ ed. Nucleonica GmbH, Karlsruhe. http://www.nucleonica.net.

23. Türler, A., Gregorich, K. E.: Experimental techniques. In: M. Schädel, D. Shaughnessy (Eds.), The Chemistry of Superheavy Elements (2014), Springer-Verlag, Berlin, Heidelberg, p. 261.

24. Düllmann, Ch. E.: Physical preseparation: a powerful new method for transactinide chemists. Eur. Phys. J. D 45(1), 75 (2007).

25. Le Naour, C., Hoffman, D. C., Trubert, D.: Fundamental and experimental aspects of single atom-at-a-time chemistry. In: M. Schädel, D. Shaughnessy (Eds.), The Chemistry of Superheavy Elements (2014), Springer-Verlag, Berlin, Heidelberg, p. 241.

26. Gäggeler, H. W., Türler, A.: Gas-phase chemistry of superheavy elements. In: M. Schädel, D. Shaughnessy (Eds.), The Chemistry of Superheavy Elements (2014), Springer-Verlag, Berlin, Heidelberg, p. 415.

27. Kratz, J. V., Nagame, Y.: Liquid-phase chemistry of superheavy elements. In: M. Schädel, D. Shaughnessy (Eds.), The Chemistry of Superheavy Elements (2014), Springer-Verlag, Berlin, Heidelberg, p. 309.

28. Eichler, R., Eichler, B.: Thermochemical data from gas-phase adsorption and methods of their estimation. In: M. Schädel, D. Shaughnessy (Eds.), The Chemistry of Superheavy Elements (2014), Springer Verlag, Berlin, Heidelberg, p. 375.

29. Eichler, B., Türler, A., Gäggeler, H. W.: Thermochemical characterization of seaborgium compounds in gas adsorption chromatography. J. Phys. Chem. A 103(46), 9296 (1999).

30. Zvara, I., Chuburkov, Yu. T., Tsaletka, R., Zvarova, T. S., Shalaevski, M. R., Shilov, B. V.: Chemical properies of element 104. Atomn. Energ. 21, 83 (1966).

31. Seaborg, G. T.: The transuranium elements. Science 104(2704), 379 (1946).

32. Eichler, B.: The behaviour of radionuclides in gas adsorption chromatographie processes with superimposed chemical reactions (chlorides). Radiochim. Acta 72(1), 19 (1996).

33. Gäggeler, H. W., Jost, D. T., Baltensperger, U., Weber, A., Kovacs, A., Vermeulen, D., Türler, A.: OLGA II, an on-line gas chemistry apparatus for applications in heavy element research. Nucl. Instrum. Methods Phys. Res. A 309, 201 (1991).

34. Türler, A.: Gas phase chemistry experiments with transactinide elements. Radiochim. Acta 72, 7 (1996).

35. Yakushev, A. B., Timokhin, S. N., Vedeneev, M. V., Honggui, X., Zvara, I.: Comparative study of oxochlorides of molybdenum, tungsten and element 106. J. Radioanal. Nucl. Chem. 205, 63 (1996).

36. Timokhin, S. N., Yakushev, A. B., Xu, H., Perelygin, V. P., Zvara, I.: Chemical identification of element 106 by thermochromatography. J. Radioanal. Nucl. Chem. Lett. 212, 31 (1996).

37. Zvara, I., Yakushev, A. B., Timokhin, S. N., Honggui, X., Perelygin, V. P., Chuburkov, Yu. T.: Chemical identification of element 106 (thermochromatography of oxochlorides). Radiochim. Acta 81, 179 (1998).

38. Schädel, M., Brüchle, W., Dressler, R., Eichler, B., Gäggeler, H. W., Günther, R., Gregorich, K. E., Hoffman, D. C., Hübener, S., Jost, D. T., Kratz, J. V., Paulus, W., Schumann, D., Timokhin, S., Trautmann, N., Türler, A., Wirth, G., Yakuschev, A.: Chemical properties of element 106 (seaborgium). Nature 388, 55 (1997).

39. Türler, A., Brüchle, W., Dressler, R., Eichler, B., Eichler, R., Gäggeler, H. W., Gärtner, M., Glatz, J. P., Gregorich, K. E., Hübener, S., Jost, D. T., Lebedev, V. Y., Pershina, V. G., Schädel, M., Taut, S., Timokhin, S. N., Trautmann, N., Vahle, A., Yakushev, A. B.: First measurement of a thermochemical property of a seaborgium compound. Angew. Chem. Int. Ed. 38, 2212 (1999).

40. Eichler, R., Brüchle, W., Dressler, R., Düllmann, C. E., Eichler, B., Gaeggeler, H. W., Gregorich, K. E., Hoffman, D. C., Hubener, S., Jost, D. T., Kirbach, U. W., Laue, C. A., Lavanchy, V. M., Nitsche, H., Patin, J. B., Piguet, D., Schaedel, M., Shaughnessy, D. A., Strellis, D. A., Taut, S., Tobler, L., Tsyganov, Y. S., Tuerler, A., Vahle, A., Wilk, P. A., Yakushev, A. B.: Chemical characterization of bohrium (element 107). Nature 407, 63 (2000).

41. Düllmann, C. E., Eichler, B., Eichler, R., Gäggeler, H. W., Jost, D. T., Piguet, D., Türler, A.: IVO, a device for in situ volatilization and on-line detection of products from heavy ion reactions. Nucl. Instrum. Methods Phys. Res. A 479, 631 (2002).

42. Düllmann, Ch. E., Eichler, B., Eichler, R., Gäggeler, H. W., Jost, D. T., Piguet, D., Türler, A.: On the stability and volatility of group 8 tetroxides, MO4 ( $\mathrm{M}=$ ruthenium, osmium, and hassium $(Z=108))$. J. Phys. Chem. B 106, 6679 (2002).

43. Kirbach, U. W., Folden, C. M., III; Ginter, T. N., Gregorich, K. E., Lee, D. M., Ninov, V., Omtvedt, J. P., Patin, J. B., Seward, N. K., Strellis, D. A., Sudowe, R., Türler, A., Wilk, P. A., Zielinski, P. M., Hoffman, D. C., Nitsche, H.: The cryo-thermochromatographic separator (CTS): a new rapid separation and a-detection system for on-line chemical studies of highly volatile osmium and hassium $(Z=108)$ tetroxides. Nucl. Instrum. Methods Phys. Res. A 484, 587 (2002).

44. Schädel, M.: The chemistry of superheavy elements. Acta Phys. Pol. B 34, 1701 (2003).

45. Düllmann, C. E., Brüchle, W., Dressler, R., Eberhardt, K., Eichler, B., Eichler, R., Gäggeler, H. W., Ginter, T. N., Glaus, F., Gregorich, K. E., Hoffman, D. C., Jäger, E., Jost, D. T., Kirbach, U. W., Lee, D. M., Nitsche, H., Patin, J. B., Pershina, V., Piguet, D., Qin, Z., Schäel, M., Schausten, B., Schimpf, E., Schott, H. J., Soverna, S., Sudowe, R., Thörle, P., Timokhin, S. N., Trautmann, N., Türler, A., Vahle, A., Wirth, G., Yakushev, A. B., Zielinski, P. M.: Chemical investigation of hassium (element 108). Nature 418, 859 (2002).

46. Pershina, V., Anton, J., Jacob, T.: Fully relativistic density-functional-theory calculations of the electronic structures of $\mathrm{MO}_{4}$ ( $M=\mathrm{Ru}, \mathrm{Os}$, and element $108, \mathrm{Hs}$ ) and prediction of physisorption. Phys. Rev. A 78, 032518(5) (2008).

47. Even, J., Yakushev, A., Duellmann, C. E., Dvorak, J., Eichler, R., Gothe, O., Hild, D., Jaeger, E., Khuyagbaatar, J., Kratz, J. V., Krier, J., Niewisch, L., Nitsche, H., Pysmenetska, I., Schaedel, M., 
Schausten, B., Tuerler, A., Wiehl, N., Wittwer, D.: Rapid synthesis of radioactive transition-metal carbonyl complexes at ambient conditions. Inorg. Chem. 51(12), 6431 (2012).

48. Wang, Y., Qin, Z., Fan, F. L., Haba, H., Komori, Y., Cao, S. W., Wu, X. L., Tan, C. M.: Gas-phase chemistry of technetium carbonyl complexes. Phys. Chem. Chem. Phys. 17(20), 13228 (2015).

49. Even, J., Yakushev, A., Dullmann, C. E., Haba, H., Asai, M., Sato, T. K., Brand, H., Di Nitto, A., Eichler, R., Fan, F. L., Hartmann, W., Huang, M., Jager, E., Kaji, D., Kanaya, J., Kaneya, Y., Khuyagbaatar, J., Kindler, B., Kratz, J. V., Krier, J., Kudou, Y., Kurz, N., Lommel, B., Miyashita, S., Morimoto, K., Morita, K., Murakami, M., Nagame, Y., Nitsche, H., Ooe, K., Qin, Z., Schädel, M., Steiner, J., Sumita, T., Takeyama, M., Tanaka, K., Toyoshima, A., Tsukada, K., Türler, A., Usoltsev, I., Wakabayashi, Y., Wang, Y., Wiehl, N., Yamaki, S.: Synthesis and detection of a seaborgium carbonyl complex. Science 345(6203), 1491 (2014).

50. Pershina, V., Anton, J.: Theoretical predictions of properties and gas-phase chromatography behaviour of carbonyl complexes of group-6 elements Cr, Mo, W, and element 106, Sg. J. Chem. Phys. 138, 174301 (2013).

51. Usoltsev, I., Eichler, R., Wang, Y., Even, J., Yakushev, A., Haba, H., Asai, M., Sato, T. K., Brand, H., Di Nitto, A., Düllmann, Ch. E., Fan, F. L., Hartmann, W., Huang, M., Jäger, E., Kaji, D., Kanaya, J., Kaneya, Y., Khuyagbaatar, J., Kindler, B., Kratz, J. V., Krier, J., Kudou, Y., Kurz, N., Lommel, B., Miyashita, S., Morimoto, K., Morita, K., Murakami, M., Nagame, Y., Nitsche, H., Ooe, K., Schädel, M., Steiner, J., Steinegger, P., Sumita, T., Takeyama, M., Tanaka, K., Toyoshima, A., Tsukada, K., Türler, A., Wakabayashi, Y., Wiehl, N., Yamaki, S., Qin, Z.: Decomposition studies of group 6 hexacarbonyl complexes. Part 1: production and decomposition of $\mathrm{Mo}(\mathrm{CO})_{6}$ and W(CO) $)_{6}$. Radiochim. Acta 104, 141 (2016).

52. Usoltsev, I., Eichler, R., Türler, A.: Decomposition studies of group 6 hexacarbonyl complexes. Part 2: modelling of the decomposition process. Radiochim. Acta 104, 531 (2016).

53. Nash, C. S., Bursten, B. E.: Prediction of the bond lengths, vibrational frequencies, and bond dissociation energy of octahedral seaborgium hexacarbonyl, $\mathrm{Sg}(\mathrm{CO})_{6}$. J. Am. Chem. Soc. 121, 10830 (1999).

54. Iliaš, M., Pershina, V.: Hexacarbonyls of Mo, W, and Sg: MetalCO bonding revisited. Inorg. Chem. 56, 1638 (2017).

55. Lewis, K. E., Golden, D. M., Smith, G. P.: Organometallic bond dissociation energies: laser pyrolysis of $\mathrm{Fe}(\mathrm{CO})_{5}, \mathrm{Cr}(\mathrm{CO})_{6}$, $\mathrm{Mo}(\mathrm{CO})_{6}$, and W(CO) $)_{6}$ J. Am. Chem. Soc. 106, 3905 (1984).

56. Eichler, B.: Das Flüchtigkeitsverhalten von Transactiniden im Bereich um Z=114. Kernenergie 19, 307 (1976).

57. Eichler, B., Reetz, T.: Chemical isolation of new elements. Kernenergie 25, 218 (1982).

58. Soverna, S., Dressler, R., Düllmann, C. E., Eichler, B., Eichler, R., Gaeggeler, H. W., Haenssler, F., Niklaus, J.-P., Piguet, D., Qin, Z., Tuerler, A., Yakushev, A.: Thermochromatographic studies of mercury and radon on transition metal surfaces. Radiochim. Acta 93, 1 (2005).

59. Eichler, R., Schädel, M.: Adsorption of radon on metal surfaces: a model study for chemical investigations of elements 112 and 114. J. Phys. Chem. B 106, 5413 (2002).

60. Eichler, R., Aksenov, N. V., Belozerov, A. V., Bozhikov, G. A., Chepigin, V. I., Dmitriev, S. N., Dressler, R., Gäggeler, H. W., Gorshkov, V. A., Haenssler, F., Itkis, M. G., Laube, A., Lebedev, V. Y., Malyshev, O. N., Oganessian, Y. Ts., Petrushkin, O. V., Piguet, D., Rasmussen, P., Shishkin, S. V., Shutov, A. V., Svirikhin, A.
I., Tereshatov, E. E., Vostokin, G. K., Wegrzecki, M., Yeremin, A. V.: Chemical characterization of element 112. Nature 447, 72 (2007).

61. Eichler, R., Aksenov, N. V., Belozerov, A. V., Bozhikov, G. A., Chepigin, V. I., Dmitriev, S. N., Dressler, R., Gäggeler, H. W., Gorshkov, V. A., Haenssler, F., Itkis, M. G., Laube, A., Lebedev, V. Y., Malyshev, O. N., Oganessian, Y. Ts., Petrushkin, O. V., Piguet, D., Rasmussen, P., Shishkin, S. V., Shutov, A. V., Svirikhin, A. I., Tereshatov, E. E., Vostokin, G. K., Wegrzecki, M., Yeremin, A. V.: Thermochemical and physical properties of element 112. Angew. Chem. Int. Ed. 47, 3262 (2008).

62. Pitzer, K. S.: Are elements 112, 114, and 118 relatively inert gases? J. Chem. Phys. 63, 1032 (1975).

63. Pershina, V., Chem. Reactivity of superheavy elements $\mathrm{Cn}, \mathrm{Nh}$, and $\mathrm{Fl}$ and their lighter homologues $\mathrm{Hg}, \mathrm{Tl}$, and $\mathrm{Pb}$, Respectively, with a gold surface from periodic DFT calculations. Inorg. Chem. 57(7), 3948 (2018).

64. Serov, A., Eichler, R., Dressler, R., Piguet, D., Türler, A., Vögele, A., Wittwer, D., Gäggeler, H. W.: Gas chromatography of indium in macroscopic and carrier-free amounts using quartz and gold as stationary phases. Radiochim. Acta 99, 95 (2011).

65. Serov, A., Eichler, R., Türler, A., Wittwer, D., Gäggeler, H. W., Dressler, R., Piguet, D., Vögele, A.: Adsorption interaction of carrier-free thallium species with gold and quartz surfaces. Radiochim. Acta 101, 421 (2013).

66. Pershina, V., Iliaš, M.: Electronic structure and properties of MAu and $\mathrm{MOH}$, where $\mathrm{M}=\mathrm{Tl}$ and $\mathrm{Nh}$ : new data. Chem. Phys. Lett. 694, 107 (2018).

67. Dmitriev, S. N., Aksenov, N. V., Albin, Y. V., Bozhikov, G. A., Chelnokov, M. L., Chepygin, V. I., Eichler, R., Isaev, A. V., Katrasev, D. E., Lebedev, V. Ya., Malyshev, O. N., Petrushkin, O. V., Porobanuk, L. S., Ryabinin, M. A., Sabel'nikov, A. V., Sokol, E. A., Svirikhin, A. V., Starodub, G. Ya., Usoltsev, I., Vostokin, G. K., Yeremin, A. V.: Pioneering experiments on the chemical properties of element 113. Mendeleev Commun. 24, 253 (2014).

68. Aksenov, N. V., Steinegger, P. J., Abdullin, F. S., Albin, Y. V., Bozhikov, G. A., Chepigin, V. I., Eichler, R., Lebedev, V. Y., Mamudarov, A. S., Malyshev, O. N., Petrushkin, O. V., Polyakov, A. N., Popov, Y. A., Sabelnikov, A. V., Sagaidak, R. N., Shirokovsky, I. V., Shumeiko, M. V., Starodub. G. Ya., Tsyganov, Y. S., Utyonkov, V. K., Voinov, A. A., Vostokin, G. K., Yeremin, A., Dmitriev, S. N.: On the volatility of nihonium (Nh, Z=113). Eur. Phys. J. A 53, 158 (2017).

69. Eichler, R., Aksenov, N. V., Albin, Yu. V., Belozerov, A. V., Bozhikov, G. A., Chepigin, V. I., Dmitriev, S. N., Dressler, R., Gaggeler, H. W., Gorshkov, V. A., Henderson, R. A., Johnsen, A. M., Kenneally, J. M., Lebedev, V. Ya., Malyshev, O. N., Moody, K. J., Oganessian, Yu. Ts., Petrushkin, O. V., Piguet, D., Popeko, A. G., Rasmussen, P., Serov, A., Shaughnessy, D. A., Shishkin, S. V., Shutov, A. V., Stoyer, M. A., Stoyer, N. J., Svirikhin, A. I., Tereshatov, E. E., Vostokin, G. K., Wegrzecki, M., Wilk, P. A., Wittwer, D., Yeremin, A. V.: Indication for a volatile element 114. Radiochim. Acta 98, 133 (2010)

70. Yakushev, A., Gates, J. M., Türler, A., Schädel, M., Düllmann, Ch. E., Ackermann, D., Andersson, L. L., Block, M., Brüchle, W., Dvorak, J., Eberhardt, K., Essel, H. G., Even, J., Forsberg, U., Gorshkov, A., Graeger, R., Gregorich, K. E., Hartmann, W., Herzberg, R. D., Hessberger, F., Hild, D., Hübner, A., Jäger, E., Khuyagbaatar, J., Kindler, B., Kratz, J. V., Krier, J., Kurz, N., Lommel, B., Niewisch, J., Nitsche, H., Omtvedt, J. P., Parr, E., Qin Zhi Rudolp, 
D., Runke, J., Schausten, B., Schimpf, E., Semchenkov, A., Steiner, J., Thörle Pospiech, P., Uusito, J., Wegrzecki, M., Wiehl, N.: Superheavy element flerovium (element 114) is a volatile metal. Inorg. Chem. 53, 1624 (2014).

71. Pershina, V.: Theoretical Chemistry of the heaviest elements. In: M. Schädel, D. Shaughnessy (Eds.) The Chemistry of Superheavy Elements (2014), Springer-Verlag, Berlin, Heidelberg, p. 209.

72. Eichler, B., Kratz, J. V.: Electrochemical deposition of carrier-free radionuclides. Radiochim. Acta 88, 475 (2000).

73. Hummrich, H., Banik, N. L., Breckheimer, M., Brüchle, W., Buda, R., Feist, F., Jäger, E., Kratz, J. V., Kuczewski, B., Liebe, D., Niewisch, L., Schädel, M., Schausten, B., Schimpf, E., Wiehl, N.: Electrodeposition methods in superheavy element chemistry. Radiochim. Acta 96, 73 (2008).

74. Toyoshima, A., Kasamatsu, Y., Tsukada, K., Asai, M., Kitatsuji, Y., Ishii, Y., Toume, H., Nishinaka, I., Haba, H., Ooe, K., Sato, T., Shinohara, A., Akiyama, K., Nagame, Y.: Oxidation of element 102, nobelium, with flow electrolytic column chromatography on an atom-at-a-time scale. J. Am. Chem. Soc. 131, 9180 (2009).

75. Chiera, N. M., Aksenov, N. V., Albin, Y. V., Bozhikov, G. A., Chepigin, V. I., Dmitriev, S. N., Dressler, R., Eichler, R., Lebedev, V. Ya., Madumarov, A., Malyshev, O. N., Piguet, D., Popov, Y. A., Sabelnikov, A. V., Steinegger, P., Svirikhin, A. I., Türler, A., Vostokin, G. K., Vögele, A., Yeremin, A. V.: Interaction of elemental mercury with selenium surfaces: model experiments for investigations of superheavy elements copernicium and flerovium. J. Radioanal. Nucl. Chem. 311(1), 99 (2017).

76. Borschevsky, A., Pasteka, F., Pershina, V., Eliav, E., Kaldor, U.: Ionization potentials and electron affinities of the superheavy elements 115-117 and their sixth-row homologues $\mathrm{Bi}, \mathrm{Po}$, and At. Phys. Rev. A 91, 020501(R) (2015).
77. Sato, T. K., Asai, M., Borschevsky, A., Stora, T., Sato, N., Kaneya, Y., Tsukada, K., Duellmann, Ch E., Eberhardt, K., Eliav, E., Ichikawa, S., Kaldor, U., Kratz, J. V., Miyashita, S., Nagame, Y., Ooe, K., Osa, A., Renisch, D., Runke, J., Schaedel, M., ThoerlePospiech, P., Toyoshima, A., Trautmann, N.: Measurement of the first ionization potential of lawrencium, element 103. Nature 520, 209 (2015).

78. Steinegger, P., Dressler, R., Eichler, R., Piguet, D., Streuli, S., Türler, A.: Diamond detectors for high-temperature transactinide chemistry experiments. Nucl. Instr. Meth. Phys. Res. A 850, 61 (2017).

79. Neumayr, J. B., Thirolf, P. G., Habs, D., Heinz, S., Kolhinen, S. S., Sewtz, M., Szerypo, J.: Performance of the MLL-IonCatcher. Rev. Sci. Instr. 77, 065109 (2006).

80. Jerabek, P., Schuetrumpf, B., Schwerdtfeger, P., Nazarewicz, W.: Electron and nucleon localization functions of oganesson: approaching the thomas-fermi limit. Phys. Rev. Lett. 120, 053001 (2018).

81. Eliav, E., Kaldor, U., Ishikawa, Y., Pyykkö, P.: Element 118: the first rare gas with an electron affinity. Phys. Rev. Lett. 77, 5350 (1996).

82. Goidenko, I., Labzowsky, L., Eliav, E., Kaldor, U., Pyykkö, P.: QED corrections to the binding energy of the eka-radon $\mathrm{Z}=118$ negative ion. Phys Rev. A 67, 020102(3)R (2003).

83. Fricke, B., Greiner, W., Waber, J. T.: The continuation of the periodic table up to $Z=172$. The chemistry of superheavy elements. Theoret. Chim. Acta 21, 235 (1971).

84. Nefedov, V. I., Trzhaskovskaya, M. B., Yarzhemskii, V. G.: Electronic configurations and the periodic table for superheavy elements. Dokl. Akad. Nauk 408(4), 488 (2006).

85. Pyykkö, P.: The physics behind chemistry and the periodic table. Chem. Rev. 112, 371 (2012). 